Nat. Hazards Earth Syst. Sci., 17, 2093-2107, 2017

https://doi.org/10.5194/nhess-17-2093-2017

(C) Author(s) 2017. This work is distributed under

the Creative Commons Attribution 3.0 License.

\title{
Using street view imagery for 3-D survey of rock slope failures
}

\author{
Jérémie Voumard ${ }^{1}$, Antonio Abellán ${ }^{1,2}$, Pierrick Nicolet ${ }^{1,3}$, Ivanna Penna ${ }^{1,3}$, Marie-Aurélie Chanut ${ }^{4}$, \\ Marc-Henri Derron ${ }^{1}$, and Michel Jaboyedoff ${ }^{1}$ \\ ${ }^{1}$ Risk analysis group, Institute of Earth Sciences, FGSE, University of Lausanne, Switzerland \\ ${ }^{2}$ Scott Polar Research Institute, Department of Geography, University of Cambridge, UK \\ ${ }^{3}$ Geohazard and Earth Observation team, Geological Survey of Norway (NGU), Norway \\ ${ }^{4}$ Groupe Risque Rocheux et Mouvements de Sols (RRMS), Cerema Centre-Est, France
}

Correspondence to: Jérémie Voumard (jeremie.voumard@unil.ch)

Received: 31 January 2017 - Discussion started: 9 February 2017

Revised: 28 September 2017 - Accepted: 21 October 2017 - Published: 1 December 2017

\begin{abstract}
We discuss here different challenges and limitations of surveying rock slope failures using 3-D reconstruction from image sets acquired from street view imagery (SVI). We show how rock slope surveying can be performed using two or more image sets using online imagery with photographs from the same site but acquired at different instances. Three sites in the French alps were selected as pilot study areas: (1) a cliff beside a road where a protective wall collapsed, consisting of two image sets $(60$ and $50 \mathrm{im}-$ ages in each set) captured within a 6-year time frame; (2) a large-scale active landslide located on a slope at $250 \mathrm{~m}$ from the road, using seven image sets (50 to 80 images per set) from five different time periods with three image sets for one period; (3) a cliff over a tunnel which has collapsed, using two image sets captured in a 4-year time frame. The analysis include the use of different structure from motion (SfM) programs and a comparison between the extracted photogrammetric point clouds and a lidar-derived mesh that was used as a ground truth. Results show that both landslide deformation and estimation of fallen volumes were clearly identified in the different point clouds. Results are site- and softwaredependent, as a function of the image set and number of images, with model accuracies ranging between 0.2 and $3.8 \mathrm{~m}$ in the best and worst scenario, respectively. Although some limitations derived from the generation of 3-D models from SVI were observed, this approach allowed us to obtain preliminary 3-D models of an area without on-field images, allowing extraction of the pre-failure topography that would not be available otherwise.
\end{abstract}

\section{Introduction}

Three-dimensional remote sensing techniques are becoming widely used for geohazard investigations due to their ability to represent the geometry of natural hazards (mass movements, lava flows, debris flows, etc.) and its evolution over time by comparing 3-D point clouds acquired at different time steps. For example, 3-D remote sensing techniques are helping to better quantify key aspects of rock slope evolution, including the accurate quantification of rockfall rates and the deformation of rock slopes before failure using both lidar (Rosser et al., 2005; Oppikofer et al., 2009; Royan et al., 2014; Kromer et al., 2015; Fey and Wichmann., 2017) and photogrammetrically derived point clouds (Walstra et al., 2007; Lucieer et al., 2013, Stumpf et al., 2015; Fernandes et al., 2016; Guerin et al., 2017; Ruggles et al., 2016).

Airborne and terrestrial laser scanners are commonly used techniques to obtain 3-D digital terrain models (Abellán et al., 2014). Despite their very high accuracy and resolution, these technologies are costly and often demanding from a logistical point of view. Alternatively, structure from motion (SfM) photogrammetry combined with multi-view stereo (MVS) allows the use of end-user digital cameras to generate 3 -D point clouds with a decimetre-level accuracy in a costeffective way (Westoby et al., 2012; Carrivick et al., 2016).

Whereas most of the studies in SfM literature utilise pictures that were captured intentionally (Eltner et al., 2016), the potential of using internet-retrieved pictures for 3-D reconstruction has not been fully discussed before (e.g. Snavely et al., 2008; Guerin et al., 2017). Some of the largest sources of pictures online are street view imagery (SVI) services, 
which offer $360^{\circ}$ panoramas from many roads, streets and other places around the world (Anguelov et al., 2013). They allow remote observation of areas without physical access to them, thus remaining cost-effective, with applications in navigation, tourism, building texturing, image localisation, point clouds georegistration and motion from structure from motion (Zamir et al., 2010; Anguelov et al., 2010; Klingner et al., 2013; Wang et al., 2013).

The aim of the present work is to ascertain to which extent 3-D models derived from SVI can be used to detect geomorphic changes on rock slopes.

\subsection{Street view imagery}

The most common SVI service is the well-known Google Street View (GSV) (Google Street View, 2017) that is available from Google Maps (Google Maps, 2017) or Google Earth Pro (Google Earth Pro, 2013). We used GSV as the SVI service in this study. Alternatives include Streetside by Microsoft (Streetside, 2017) and national services like Tencent Maps in China (Tencent Maps, 2017). SVI was first deployed in urban areas to offer a virtual navigation of the streets. More recently, non-urban zones have also been made accessible and are used for the analysis of rock slope failures in this paper.

GSV was first used in May 2007 for capturing pictures of streets of major US cities and has been deployed worldwide during the intervening years, including rural areas. GSV images are collected with a panoramic camera system mounted on different types of vehicles (e.g. a car, train, bike, snowmobile) or carried in a backpack (Anguelov et al., 2010).

The first-generation GSV camera system was composed of eight wide-angle lenses and it is currently composed of 15 CMOS sensors of $5 \mathrm{Mpx}$ each (Anguelov et al., 2010). The 15 raw images, which are not publicly available, are processed by Google to make a panorama view containing an a priori unknown image deformation (Fig. 1). A GSV panorama is normally taken at an interval of around $10 \mathrm{~m}$ along a linear infrastructure (road, train or path).

GSV proposes a "back-in-time" function on a certain number of locations from April 2014. In addition, other historical GSV images are available from 2007 for selected areas only. The number of available image sets varies greatly at different locations: while some places have several sets, many other locations have only one image set. The back-in-time function is especially useful for natural hazards because it is possible to compare pre- and post-events images.

The GSV process can be explained in four steps (Anguelov et al., 2010; Google Street View, 2017). (1) Pictures are acquired in the field. (2) Images are aligned: preliminary coordinates are given for each picture, extracted from sensors on the Google car that measure GNNS coordinates, speed and azimuth of the car, helping to precisely reconstruct the vehicle path. Pictures can also be tilted and realigned as needed. (3) By stitching overlapping pictures, $360^{\circ}$ panoramas are created. Google applies a series of processing algorithms to each picture to attenuate delimitations between each picture and to obtain smooth pictures transitions. (4) Panoramas are draped on 3-D models to give a panorama view close to the reality; the three lidar mounted on the Google car help to build 3-D models of the scenes. Each picture of the panorama has its own internal deformation, and the application of the processing chain described above causes inconstant deformation in the $360^{\circ}$ panorama; in addition, the end user does not have any information on or control over it.

\subsection{SfM-MVS}

SfM with MVS dense reconstruction is a cost-effective photogrammetric method to obtain a 3-D point cloud of terrain using a series of overlapping images (Luhmann et al., 2014). The prerequisites are that (1) the studied object is photographed from different points of view and (2) each element of the object must be captured from a minimum of two pictures, assuming that the lens deformation parameters are known in advance (Snavely, 2008; Lucieer et al., 2013). If these parameters are not known beforehand, three pictures are the minimum requirement (Westoby et al., 2012) and about six pictures are preferred. The particularity of SfMMVS is that prior knowledge of both intrinsic camera parameters (principal point, principal distance and lens distortion) and extrinsic camera parameters (orientation and position of the camera centre, Luhmann et al., 2014) is not needed.

The workflow of SfM-MVS normally includes the following steps: (1) feature detection and matching (Lowe, 1999), (2) bundle adjustment (Snavely et al., 2006; Favalli et al., 2011; Turner et al., 2012; Lucieer et al., 2013), (3) dense 3 -D point cloud generation (Furukawa et al., 2010; Furukawa and Ponce, 2010; James and Robson, 2012) and (4) surface reconstruction and visualisation (James and Robson, 2012).

\section{Study areas and available data}

We selected three study areas in France to generate point clouds from GSV images. This country was chosen because GSV covers the majority of the roads and because the timeline function works in most of the areas covered by GSV, meaning that several periods of acquisition are available. Moreover, landslide events occur regularly on French alpine roads. The aerial view of the three areas is shown in Fig. 2a and examples of corresponding GSV images are in Fig. $2 b$ and $\mathrm{c}$.

The first case study (Basse Corniche site) is a $20 \mathrm{~m}$ high cliff beside a main road in Roquebrune-Cap-Martin connecting the town of Menton to the Principality of Monaco, in southeastern France. A wall built to consolidate the cliff collapsed after an extreme rainfall event in January 2014, blocking the road (Nice-Matin, 2014). Two 3-D models were built 

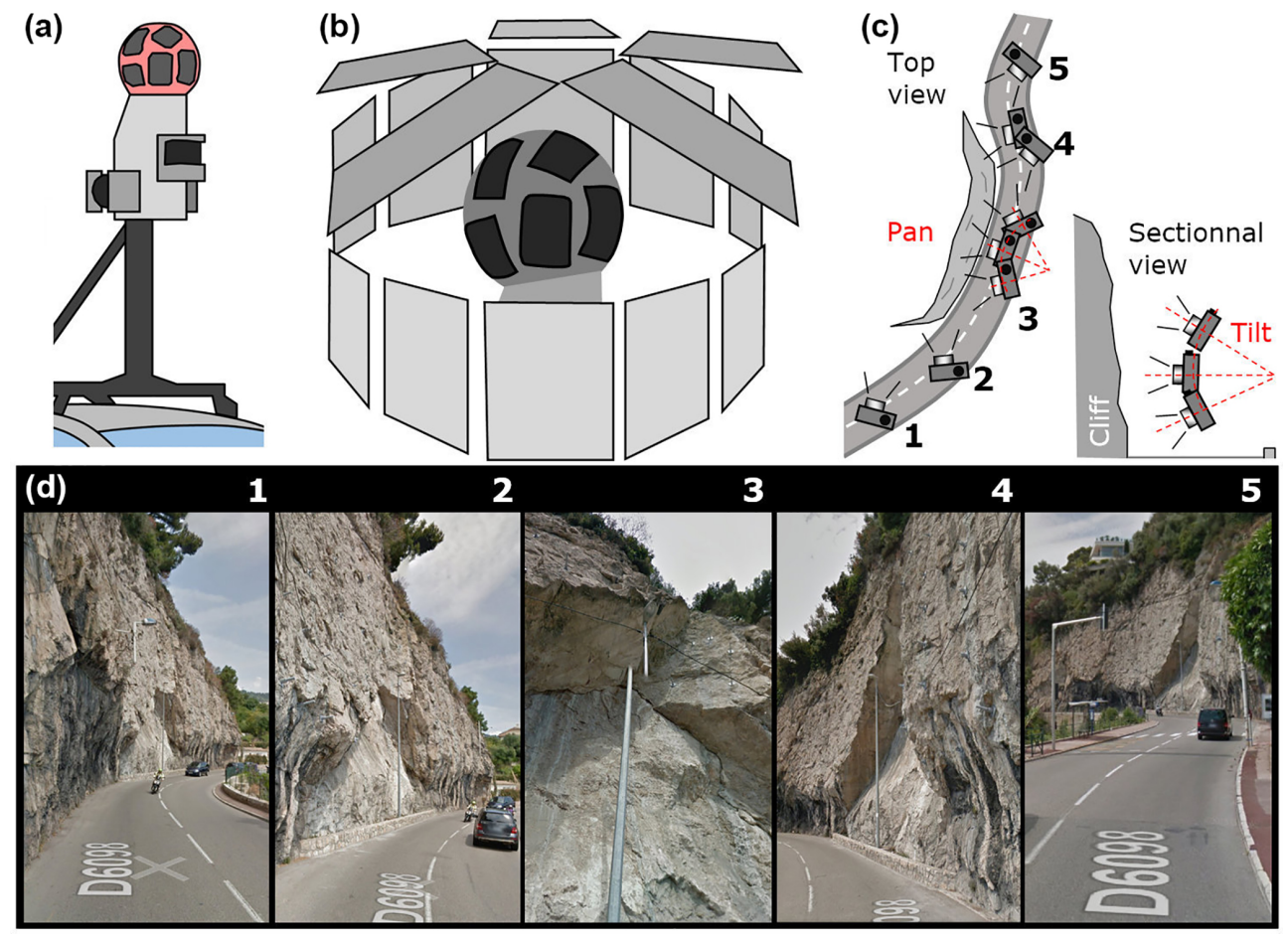

Figure 1. Google Street View (GSV) imagery functioning. (a) Schema of the GSV spherical camera system mounted on a car roof. Sensors in black are lidar, on to which the GSV images are draped (based on Google Street View, 2017; http://www.google.com/maps/about/ behind-the-scenes/streetview). (b) Functioning of the GSV spherical panorama built with 15 images. (c) Strategy of the GSV service for SfMMVS photogrammetry. Numbers correspond schematically to the images in panel (d). (d) Screen captures of GSV photos from study site 1. The image numbers correspond to those in panel (c). Note the gap on the street lamp in image 3 due to the panorama construction from the GSV pictures.

with 60 GSV images taken in 2008 before the wall collapse and 50 GSV images taken in 2014 after the event.

The second case studies is the Séchilienne landslide, located $15 \mathrm{~km}$ southeast of Grenoble (Isère department, France). The active area threatens the departmental road RD 1091 connecting the towns of Grenoble and Briançon as well as ski resorts L'Alpe d'Huez and Les Deux Alpes to the plain. This landslide is about $800 \mathrm{~m}$ long by $500 \mathrm{~m}$ high and it has been active for more than 30 years (Le Roux et al., 2009; Durville et al., 2011; Dubois et al., 2014). The shortest distance between the landslide foot and the former road is $250 \mathrm{~m}$ and the longest distance between the landslide head and the road is $1 \mathrm{~km}$. A new road, located higher on the opposite slope, has been open since July 2016. Different SfM-MVS processes were tested, using 50-80 GSV images, at six different times from April 2010 to June 2015.

The third case study is located in Arly gorges, between Ugine and Megève, on the path of Albertville-ChamonixMont-Blanc. A rockfall of about $8000 \mathrm{~m}^{3}$ affected the road at the entry of a tunnel on January 2014 (France 3, 2014). Different sets of 60-110 GSV images were processed in order to obtain three 3-D models of the road, the tunnel entry and the cliff above the tunnel.
We used two image sets for the first study site, eight image sets for the second study site and four image sets for the third study site, with dates ranging from May 2008 to December 2016, as described in Table 1.

\section{Methodology}

The first step to create SfM-MVS with SVI is to obtain images from a SVI service. GSV has been used in this study (Fig. 1). Given that original images from Google cameras are not available, one of two ways to get images from GSV is to manually extract them from the GSV panoramas. We took print screens $(1920 \times 1200$ pixels, $2.3 \mathrm{Mpx})$ of GSV panoramas of the studied areas at each acquisition step, separated by about $10 \mathrm{~m}$, from Google Maps. Several images were taken from the same point of view with different pan and tilt angles (Fig. 1c) when the studied object was too close to the road. In such cases, it was impossible to have the entire area in one image because the image is not wide enough to capture the entire studied area (for example, a $10 \mathrm{~m}$ high cliff along road). When the studied area was far away from the road, we took print screens of zoomed sections of the panorama. 

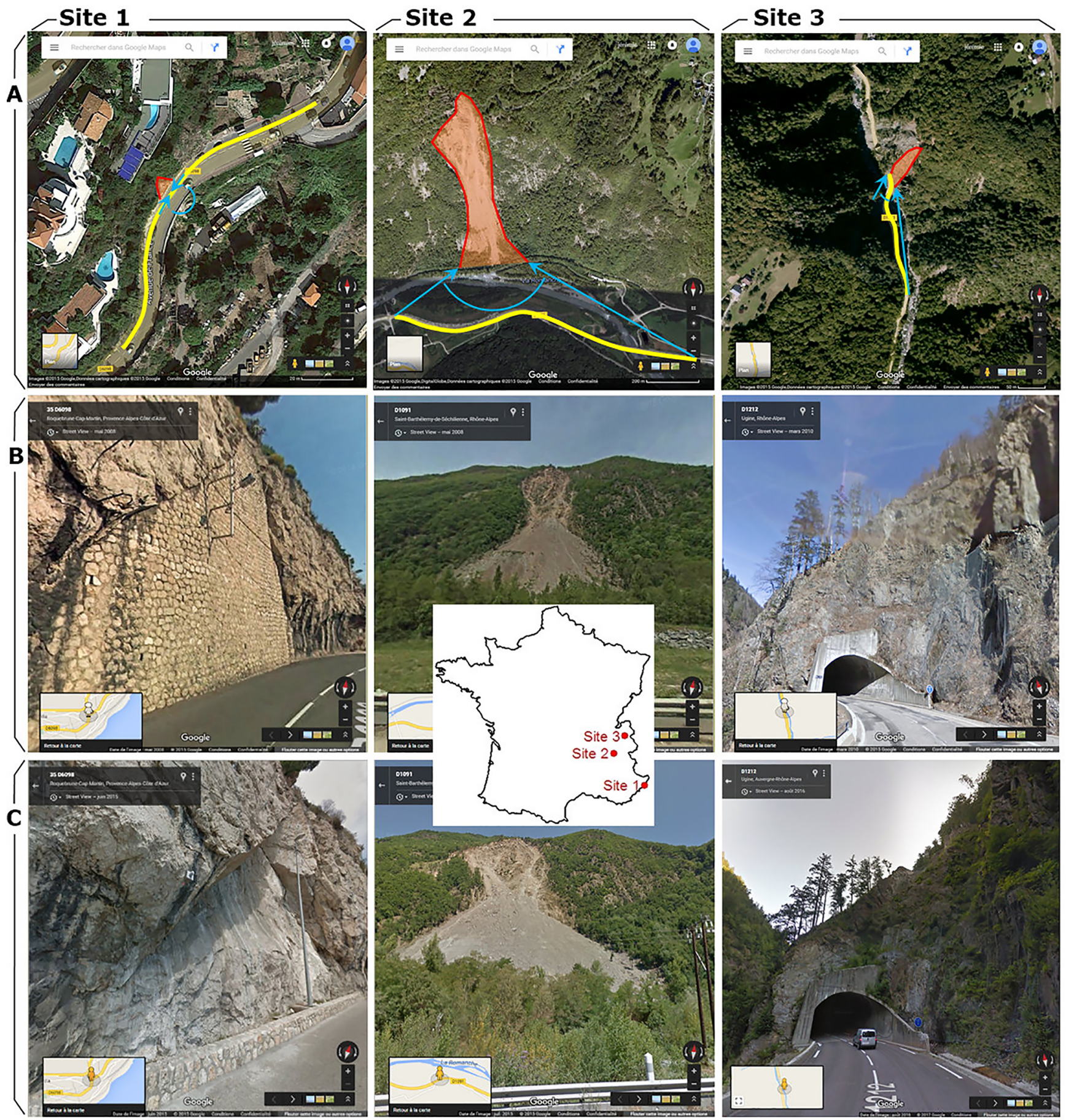

Figure 2. The three French sites (1: Basse Corniche; 2: Séchilienne; 3: Arly gorges). (a) Google Maps aerial view of the sites (in red) with the road path (yellow) used to take the GSV images of the scenes and the view angle (blue) of the images point of view around the sites. (b) First GSV of the sites. (c) Last GSV of the sites.

To perform temporal comparisons at each site, images were taken at the different dates proposed by GSV with pre- and post-event image sets. We used the SfM-MVS program VisualSFM $(\mathrm{Wu}, 2011)$ for dense point cloud reconstruction for the print screen images from Google Maps and we used CloudCompare (Girardeau-Montaut, 2011) for point cloud visualisation and comparison. Comparison between two point clouds was made using point-to-mesh strategy. To this end, a mesh was generated from the reference point cloud (the point cloud with the oldest images for site 1 or the 


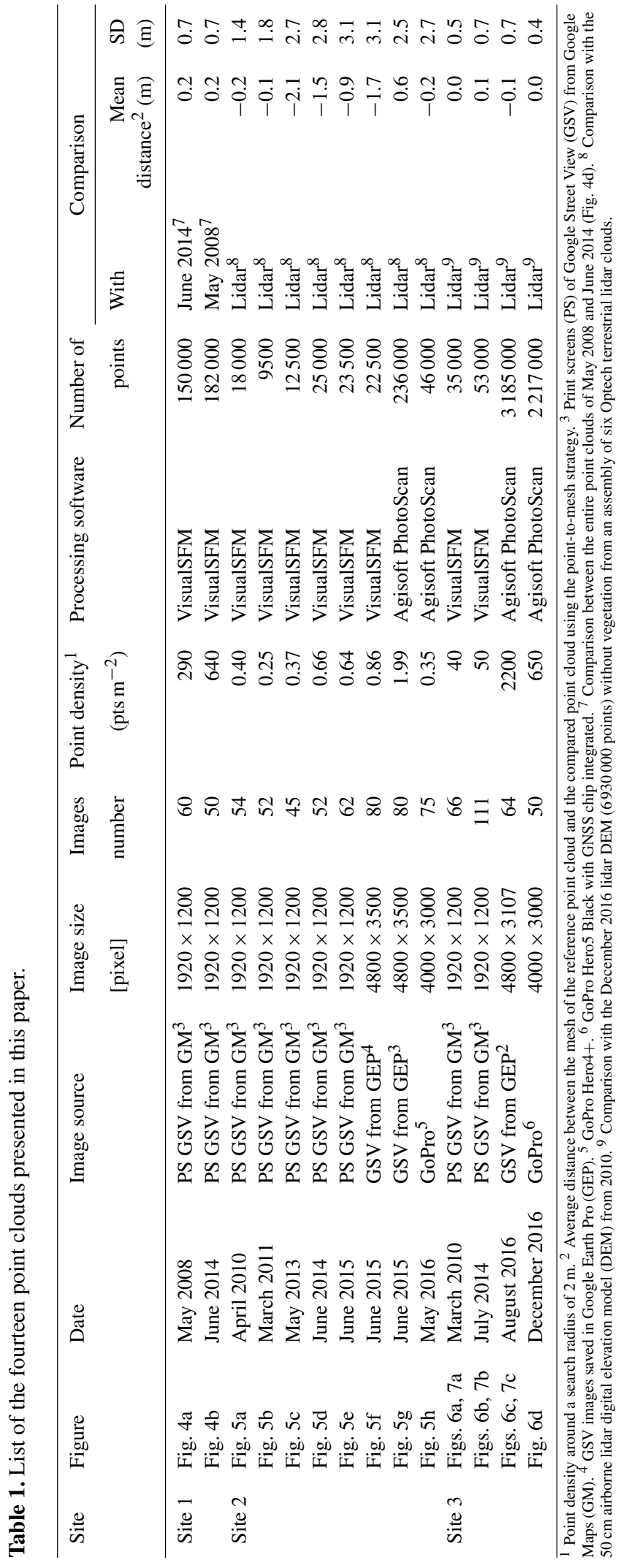

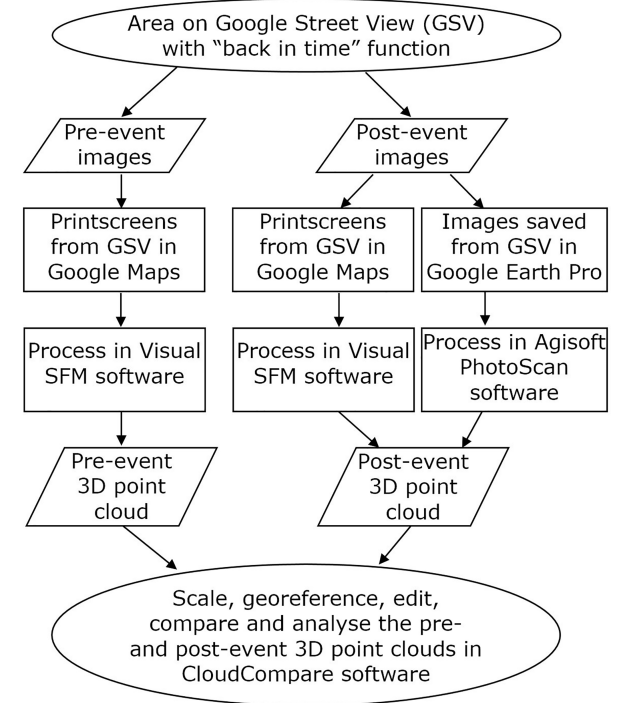

Figure 3. Flowchart of the SfM-MVS processing with GSV images on an area with the back-in-time function available. Pre-event images are displayed using the back-in-time function in GSV. Postevent images arise either from print screens of GSV in Google Maps using or not the back-in-time function or from GSV images saved in Google Earth Pro. In this last case, the last available proposed GSV images have a greater resolution as the print screens and can be processed in the Agisoft PhotoScan.

lidar scans for sites 2 and 3 ) and then the other point cloud was compared to this reference mesh. The computed shortest distance, a signed value, between the mesh and the point cloud is the length of the 3-D vector from the mesh triangle to the 3-D point. Thus, average distances and standard deviations for each comparison of point clouds were computed. Point density of point clouds was obtained using the "point density" function in CloudCompare with the "surface density" option.

Beside the images taken from print screens as described above, we also obtained GSV images $(4800 \times 3500$ pixels, $16.8 \mathrm{Mpx}$ ) from Google Earth Pro on sites 2 and 3 with the "save image" function. This second way to get GSV allows us to get images with a higher resolution than print screen images. Unfortunately, there is no timeline (or back-in-time) function in Google Earth Pro; it is only possible to save images from the last picture acquisition, i.e. generally postevent images. GSV images from Google Earth Pro were processed with the Agisoft PhotoScan software (Agisoft, 2015) for dense point cloud reconstruction, which provides much better results than VisualSFM. GSV images from Google Map were processed with VisualSFM because Agisoft was not able to process those print screens. The flowchart of Fig. 3 shows the processing applied to both types of images (print screens and saved images).

A rough scaling and georeferencing of the 3-D point clouds was made with only the coordinates of a few points 
extracted from Google Maps or from the French geoportal (Géoportail, 2016) and without ground control points.

It is important to mention here that a series of issues is expected when attempting to use SVI for 3-D model reconstruction with SfM-MVS. GSV images are constructed as $360^{\circ}$ panoramas from a series of pictures, so the internal deformation of the original image is not fully retained on the panoramas. In other words, the deformation of a cropped section of the panorama will be a main function not only of the internal deformation of the camera and lens but also of the panorama reconstruction process; this circumstance will significantly influence the bundle adjustment process and thus the 3-D reconstruction.

In addition, GoPro Hero4+ images from a moving vehicle on the road were taken by the authors at site 2 , as well a series of images captured using a GoPro Hero5 Black camera standing on site 3 (image resolution of $4000 \times 3000$ pixels, $12 \mathrm{Mpx}$ ). Six lidar scans were also taken at site 3 . This information was used for quality assessment purposes.

\section{Results and discussion}

Different results are obtained depending on the software used for SfM-MVS processing. For all case studies, VisualSFM gave results with print screens from GSV in Google Maps while Agisoft PhotoScan could not align those print screens despite adding a series of control points measured with Google Earth Pro. Resolution of print screen images seem to be insufficient for processing with Agisoft PhotoScan. However, with higher point density and empty areas, Agisoft PhotoScan provided better results with images from Google Earth Pro than VisualSFM.

\subsection{Site 1 - Basse Corniche site}

It was possible at the Basse Corniche site to estimate the fallen volume by scaling and comparing the 2008 (Fig. 4a) and 2010 (Fig. 4b) point clouds. The 2008 point cloud is composed of 150000 points with an average density of 290 points $\mathrm{m}^{2}$, and the 2014 point cloud is composed of 182000 points with an average density of 640 points $\mathrm{m}^{2}$ (Table 1). VisualSFM could align the images and make 3-D models before and after the wall collapse. It was possible to roughly scale and georeference the scene with the road width and a few point coordinates measured on Google Earth Pro or on the French geoportal. After aligning the two 3-D point clouds, meshes were built to compute the collapsed volume. The point-to-mesh alignment in CloudCompare of both point clouds was done on a small, stable part of the cliff (Fig. 4c) with a standard deviation of the point-to-mesh distance of about $10 \mathrm{~cm}$ (Fig. 9 and Table 2) and on the entire cliff beside the vegetation with a standard deviation of about $25 \mathrm{~cm}$ (Fig. 4e). In the collapsed area, the maximal horizontal distance between the two datasets is about $3.9 \mathrm{~m}$ (indicated in red in Fig. 4d). The collapsed volume (including a possible empty space between the cliff and the wall before the event) was estimated to be about $225 \mathrm{~m}^{3}$ using the point cloud comparison. Based on Google Street images, we manually estimated the dimensions of this volume $(15 \mathrm{~m}$ long $\times 10 \mathrm{~m}$ high $\times 1.5 \mathrm{~m}$ deep), getting a similar value.

The obtained point clouds at site 1 allow us to detect objects of a few decimetres. This accuracy was adequate to estimate the collapsed volume with an accuracy similar to the estimation made by hand based on the GSV photos and distances measured on Google Earth Pro and the French geoportal. This relatively high accuracy is due to the following factors: good image quality, reduced distance between the cliff and camera locations, good lighting conditions, absence of obstacles between the camera location and the area under investigation, no vegetation and efficient repartition of point of view around the cliff (Fig. 2a).

\subsection{Site 2 - Séchilienne landslide}

Eight point clouds, of which seven were derived through the SfM-MVS process with GSV images, were generated for the Séchilienne landslide at six different time steps (from April 2010 to June 2015). Three different image sources were used: GSV print screens from Google Maps, GSV images saved from Google Earth Pro and images from a GoPro HERO4+ camera from a moving vehicle (Fig. 5 and Table 1). Two different programs (VisualSFM and Agisoft PhotoScan) were used for image treatment depending on the image sources (Fig. 3 and Table 1). The number of 3-D points on the landslide area varies from 9500 to 22500 points for a processing with VisualSFM with an average density of 0.25 to 0.85 points $\mathrm{m}^{2}$, while 2360003 -D points were generated when using Agisoft PhotoScan with an average density of 2 points $\mathrm{m}^{2}$ (Table 1 ). In comparison, 1500000 points were obtained on the same area using terrestrial photogrammetry with a $24 \mathrm{Mpx}$ reflex camera.

Results were aligned on a $50 \mathrm{~cm}$ resolution airborne lidar scan of the landslide acquired in 2010 . Then, the street view SfM-MVS point clouds were aligned and compared with a mesh from the lidar scan using the point-to-mesh strategy. The alignment between the lidar point cloud and SfM-MVS point clouds derived from SVI is a key factor to define the quality of the cloud comparison. This alignment on stable areas (manually selected) was not easy to perform because of the low density of points on the SfM-MVS clouds derived from SVI. We noted a huge difference in the number of points between the different SfM-MVS clouds derived from SVI. This difference in the number of points shows the impact of the image quality. Images with a good quality (resolution, exposition, sharpness) will give point clouds with a higher number of points as point clouds from low-quality images.

A comparison of results from SfM-MVS point clouds derived from SVI and the airborne lidar scan highlights surface changes in the Séchilienne landslide over the years (Fig. 8 

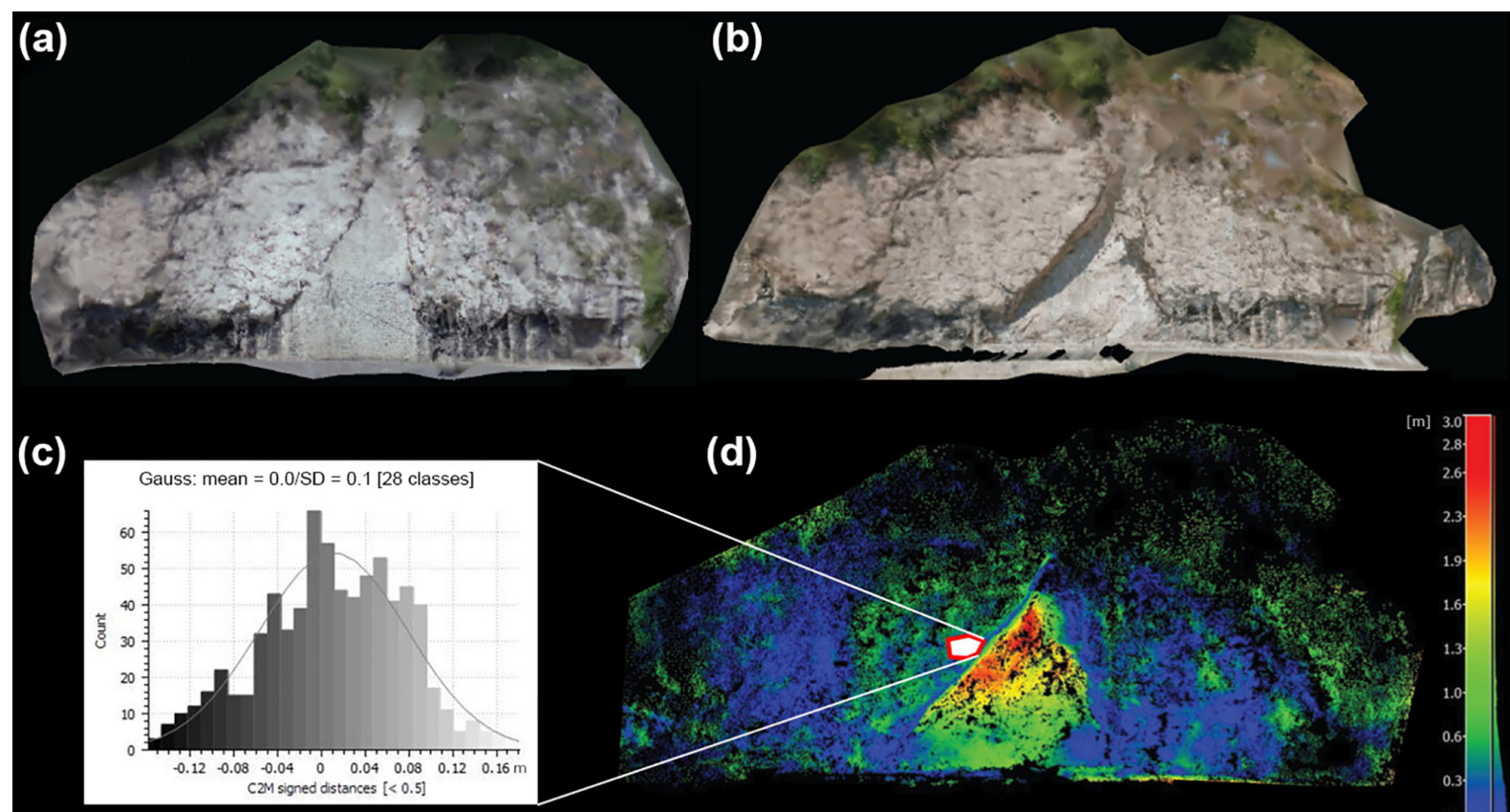

(d)
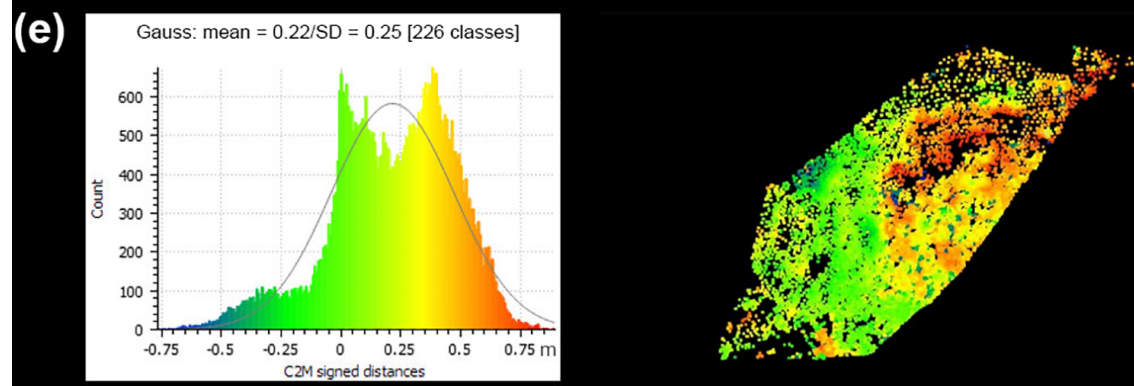

$15 \mathrm{~m}$
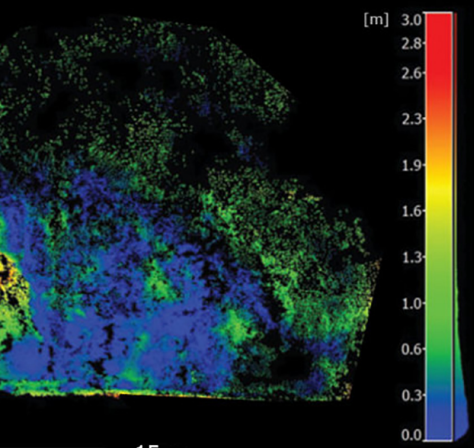

Figure 4. Results at site 1, Basse Corniche. (a) Three-dimensional model produced with GSV images taken before the event in 2008. (b) Three-dimensional model produced with GSV images taken after the event in 2014. (c) Statistics on a small part of the wall (red polygon in panel d) of 7510 points between the two point clouds with the point-to-mesh strategy in the CloudCompare. (d) Comparison of the two point clouds of 2008 and 2014 on the entire surface of the 3-D point clouds. The maximal horizontal depth of the cliff is about $3.9 \mathrm{~m}$. (e) Comparison of the two point clouds of 2008 and 2014 on the entire stable parts of the cliff (i.e. without vegetation) by not taking into account the collapsed wall (black triangle in the centre of the point clouds). The information on the picture source, date, point density and program used is given in Tables 1 and 2.

and Table 1). The 2010 point cloud (Fig. 5a2) compared with the 2010 lidar scan does not show any significant changes. Small orange and red dots are spread out on the entire landslide surface suggesting artefacts and not a real slope change. The 2010-2011 point cloud comparison (Fig. 5b2) shows little red (material accumulation) in the deposition and in the failure areas. The 2016 point cloud (Fig. 5c2) highlights material deposition in red, in the left part. This is confirmed by a comparison of a 2013 terrestrial lidar. The blue pattern indicates a loss of material in the failure and the toe areas. The 2014 point cloud (Fig. 5d2) shows similar results to the 2013 point cloud but with a light increase of material in the deposition area and rock loss in the failure area. The 2010 to 2014 point clouds (Fig. 5a-d) were processed with VisualSFM with GSV print screens in Google Maps (Table 1).
Three 2015 point clouds were processed: the first with VisualSFM and GSV print screens (Fig. 5e), the second with VisualSFM with GSV images from Google Earth Pro (Fig. 5f) and the third with Agisoft PhotoScan with images from Google Earth Pro (Fig. 5g). The results should be the same for the three point clouds, but we noticed significant differences. The 2015 point cloud processed with VisualSFM and GSV images from Google Earth Pro $(4800 \times 3500$ pixels) has a higher point density than the 2015 point cloud processed with GSV print screens $(1920 \times 1200$ pixels $)$. The 2015 point cloud with Agisoft PhotoScan and images from Google Earth Pro has a significantly higher point density (Table 1). The accumulation material (red in the left part) in the deposition area is clearly observable on the three 2015 point clouds as the rock displacement toppling below the failure area (red pattern in the failure area viewed as a material 

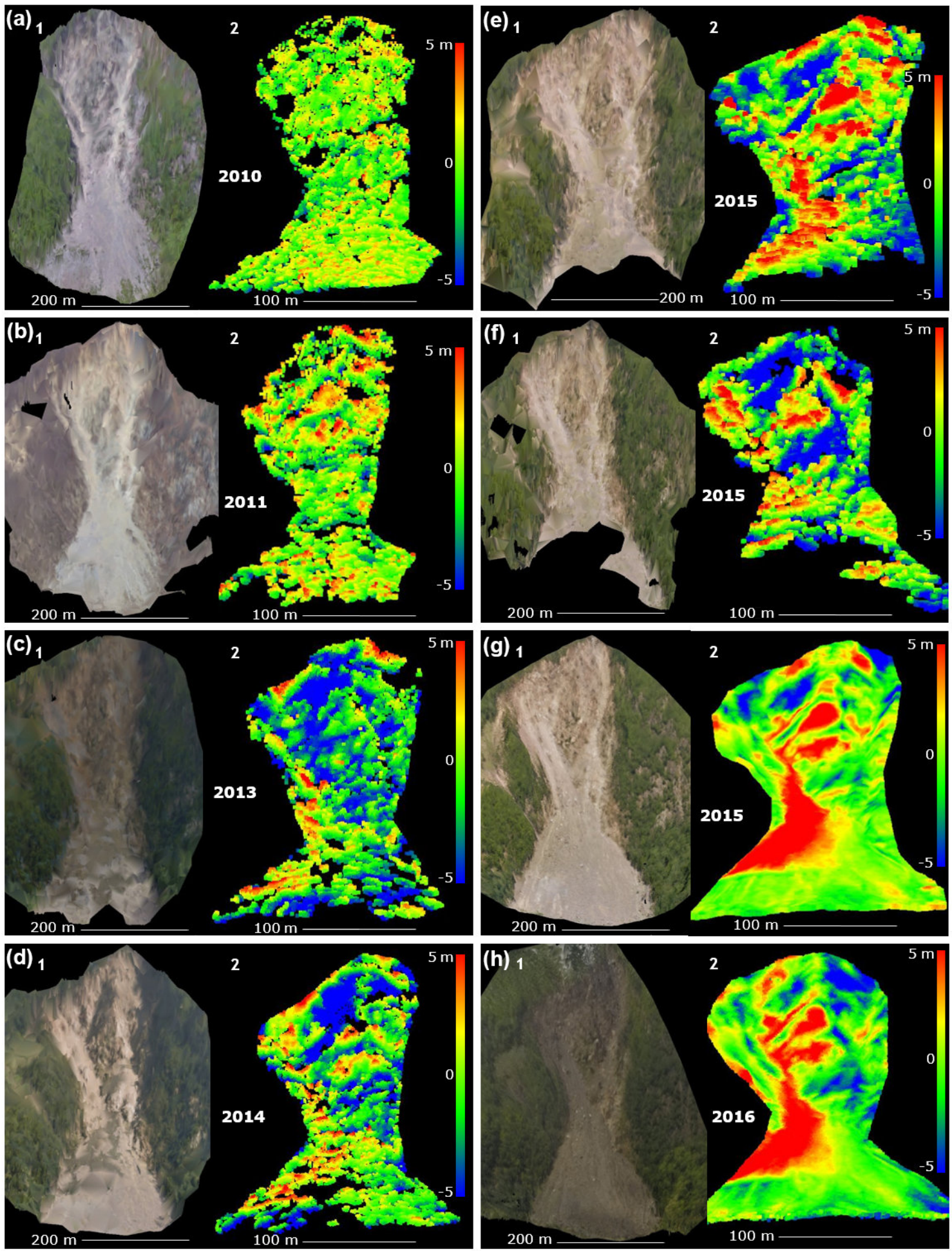

Figure 5. Results at site 2, Séchilienne. Eight point clouds from different image sets taken at six different time with three different image sources and processed with two different programs. (a1-h1) Meshs resulting from the respective point clouds. (a2-h2) Point cloud comparison with a $50 \mathrm{~cm}$ lidar digital elevation model from 2010 (red points is material increase; blue points are material decrease from the 2010 lidar cloud) with the point-to-mesh strategy in CloudCompare. The information on the picture source, date, point density and program used is given in Table 1. 


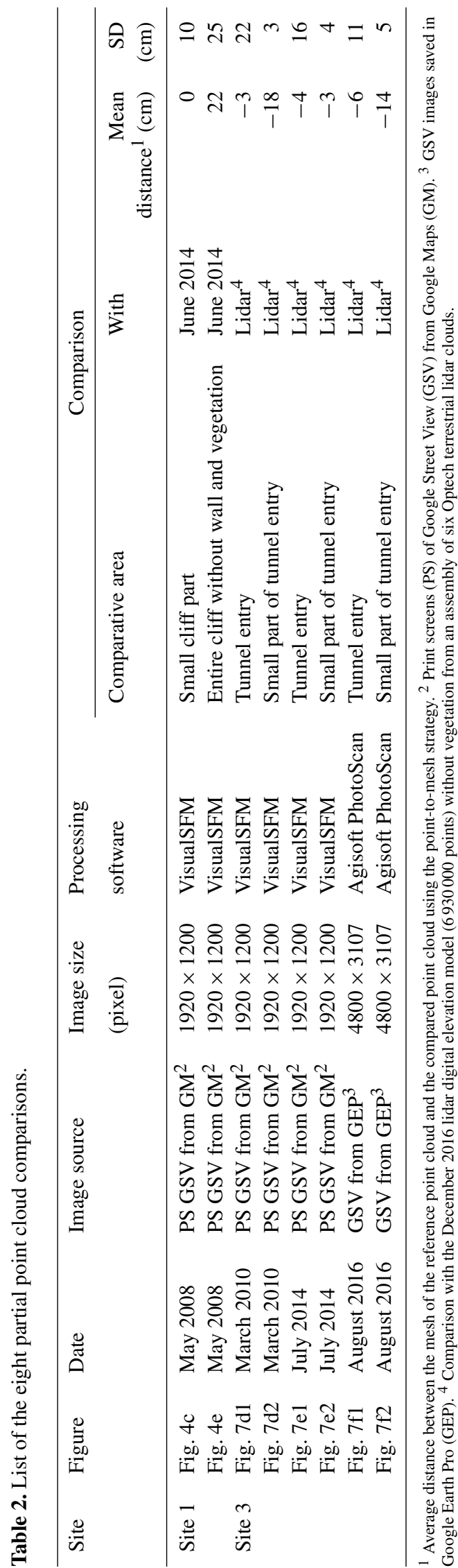

accumulation from the road). The loss of material (blue) is also easily observable in the failure area and, to a lesser extent, in the right part of the deposition area. The last 2015 point cloud is very similar to the 2016 GoPro point cloud (Fig. 5h2), which confirms the results of SfM-MVS processing with GSV images.

Results of site 2 show that images with low resolution and with low lighting generated a lower number of points compared to the models generated with the last generation of GSV cameras, having higher resolution, more advanced sensors and pictures taken with favourable lighting conditions. The large distance between the road and the landslide considerably limits the final accuracy due to low image resolution, as discussed in Eltner et al. (2016); the closest distance between the road and the centre of the landslide is $500 \mathrm{~m}$ and the largest distance between the upper part of the landslide and the point of view is about $1400 \mathrm{~m}$. Furthermore, the vegetation on the landslide foot and along the road as well as a power line partially obstruct the visibility of the study area. In addition, clouds are present on several images on the top of the scarp, degrading the upper part of the 3-D point cloud.

\subsection{Site 3 - Arly gorges}

Four point clouds, of which three were derived from the SfM-MVS process using GSV images, were generated at the Arly gorges site at four different times (from March 2010 to December 2016). Three different image sources (GSV print screens from Google Maps, GSV images exported from Google Earth Pro and our own images acquired from a GoPro HERO5 Black) were used (Fig. 6 and Table 1). Two different programs (VisualSFM and Agisoft PhotoScan) were tested. In addition, a lidar point cloud resulting from an assembly of six Optech ILRIS scans has been used as ground truth (Fig. 6e). The number of points varies from 35000 points to 3.2 million points with an average density of 40 to 2200 points $\mathrm{m}^{2}$ (Table 1 ).

The 3-D point cloud from the GoPro Hero5 Black images has been roughly georeferenced, scaled and oriented thanks to the GNSS chip integrated in the camera and has been controlled and refined with points coordinates extracted from Google Maps and the French geoportal. The three point clouds processed from GSV images and the lidar scan have been roughly aligned to this reference. Then the four SfMMVS point clouds (three with GSV images and one with GoPro images) were precisely aligned and scaled on the lidar point cloud, which was considered to be the reference cloud.

The analysis (Fig. 9, Tables 1 and 2) shows that the 2010 model derived from GSV images processed with VisualSFM gives the least accurate results (Figs. 6a and 7a): we hardly perceive the wall of the tunnel entry and the wide cliff structures. The results of the 2014 point cloud from GSV images processed with the same program are slightly better (Figs. $6 \mathrm{~b}$ and $7 \mathrm{~b}$ ): the right-hand tunnel entry is modelled while it was 


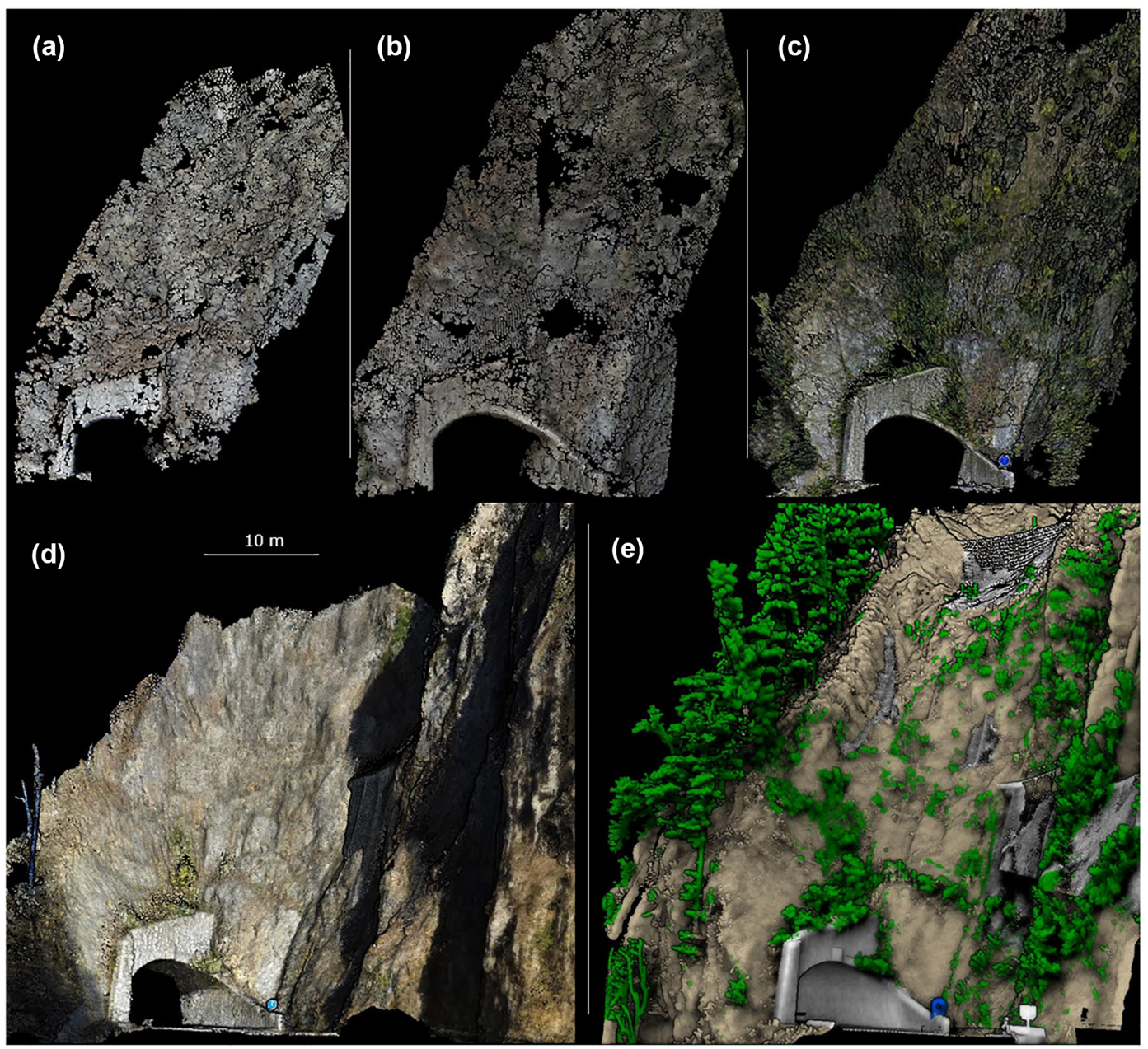

Figure 6. Results at site 3, the Arly gorges. Five point clouds from four different image sets sources and processed with two different softwares and one lidar scan. (a) March 2010 point cloud. (b) July 2014 point cloud. (c) August 2016 point cloud. (d) December 2016 point cloud taken on foot with a GoPro camera. (e) December 2016 lidar cloud from an assembly of six Optech terrestrial lidar scans. The grey elements in the cliff are the protective nets.

not the case on the 2010 point cloud. The point cloud processed in Agisoft PhotoScan derived from 2016 GSV images saved from Google Earth Pro displays much better quality than the previous (Figs. 6c and 7c): we now see the protective nets in the slope as well as the blue road sign announcing the tunnel. The vegetation is also observable and the tunnel entry is similarly modelled as the 2016 GoPro point cloud (Fig. 6d).

The SfM-MVS point cloud derived from GoPro images gives a significantly better representation of the whole scene, especially on the top of the model. Slope structures and protective nets are well modelled, but the small vegetation is not. The comparison between the 2016 lidar scan (Fig. 6e) and the three SfM-MVS with GSV images point clouds does not allow us to identify terrain deformation on the cliff. Moreover, the source area of the rockfall is not observable from the GSV images because it is located higher in the slope, outside of the images.
A great majority of points consistently displayed distances between the lidar scan mesh and the SfM-MVS point clouds ranging between $\pm 2 \mathrm{~m}$ (Fig. 7a-c). Protective nets degrade the results because they generate badly modelled surfaces corresponding to the nets on some cliff sections (such as the red-blue section on the top-right of the July 2014 cloud; Fig. 7a). Considering the tunnel entry (Fig. 7d-f) the average distance from point clouds to lidar mesh varies from -3 to $-6 \mathrm{~cm}$ (depends mainly on the alignments of the clouds). Standard deviations vary from $22 \mathrm{~cm}$ for the 2010 point cloud to $11 \mathrm{~cm}$ for the 2016 point cloud. On a part of the wall above the tunnel (grey polygon in Fig. $7 \mathrm{~d}-\mathrm{f}$ ), the average distance point cloud - lidar mesh varies from -3 to $-18 \mathrm{~cm}$ with standard deviations of $3 \mathrm{~cm}$ for the 2010 point cloud, $4 \mathrm{~cm}$ for the 2014 point cloud and $6 \mathrm{~cm}$ for the 2016 point cloud (Fig. 9 and Table 2). We observe again at this site that the improvement of the GSV camera resolution and image quality im- 

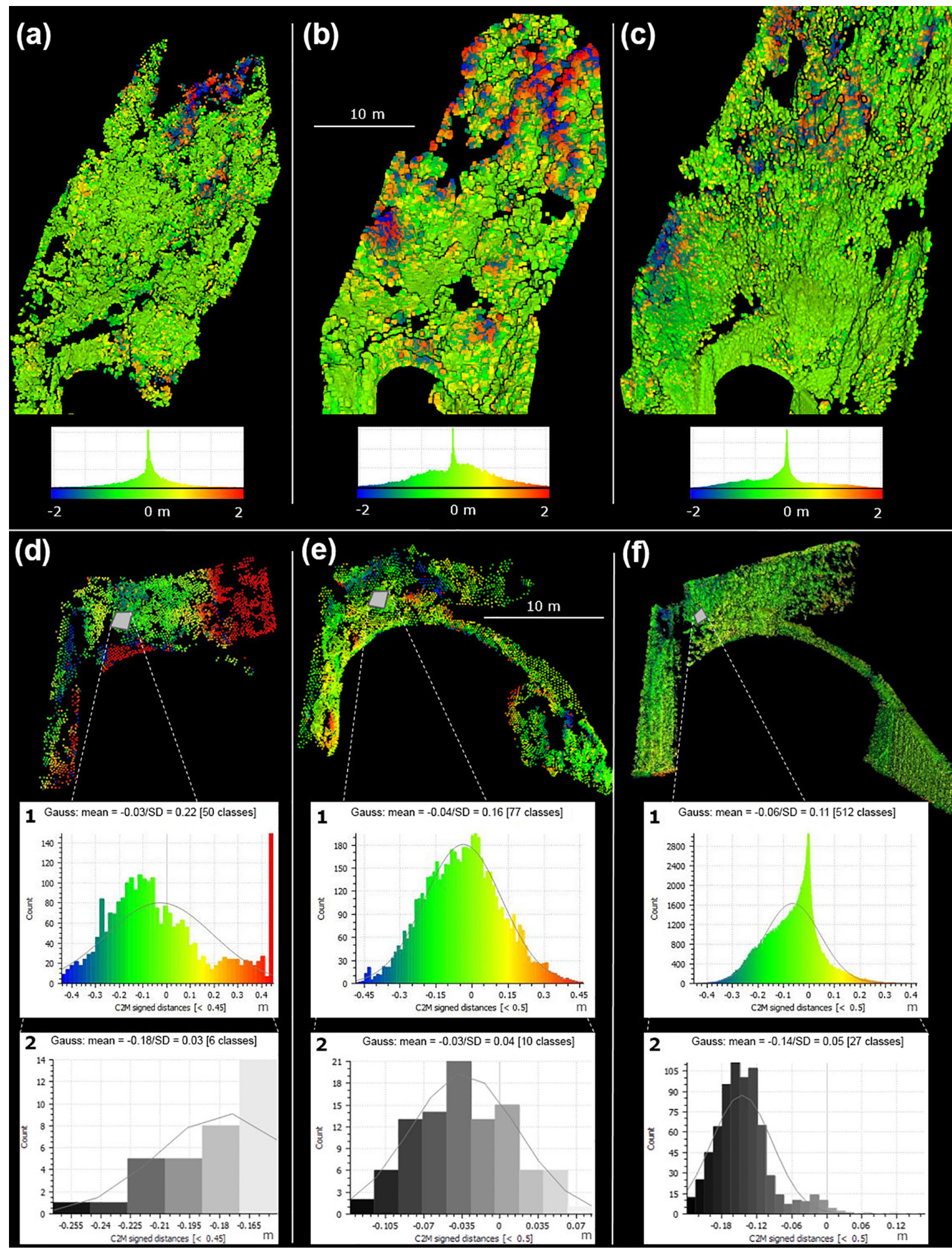

Figure 7. (a-c) March 2010, July 2014 and August 2016 point clouds compared with December 2016 lidar digital elevation model (DEM; red points are material increase; blue points are material decrease from the 2016 lidar cloud) with the point-to-mesh strategy on the CloudCompare. (d-f) Tunnel entry and part of the wall overlooking the tunnel (grey polygon) of the March 2010, July 2014 and August 2016 point clouds compared with December 2016 lidar DEM. The information on the picture source, date, point density and program used is given in Tables 1 and 2. 


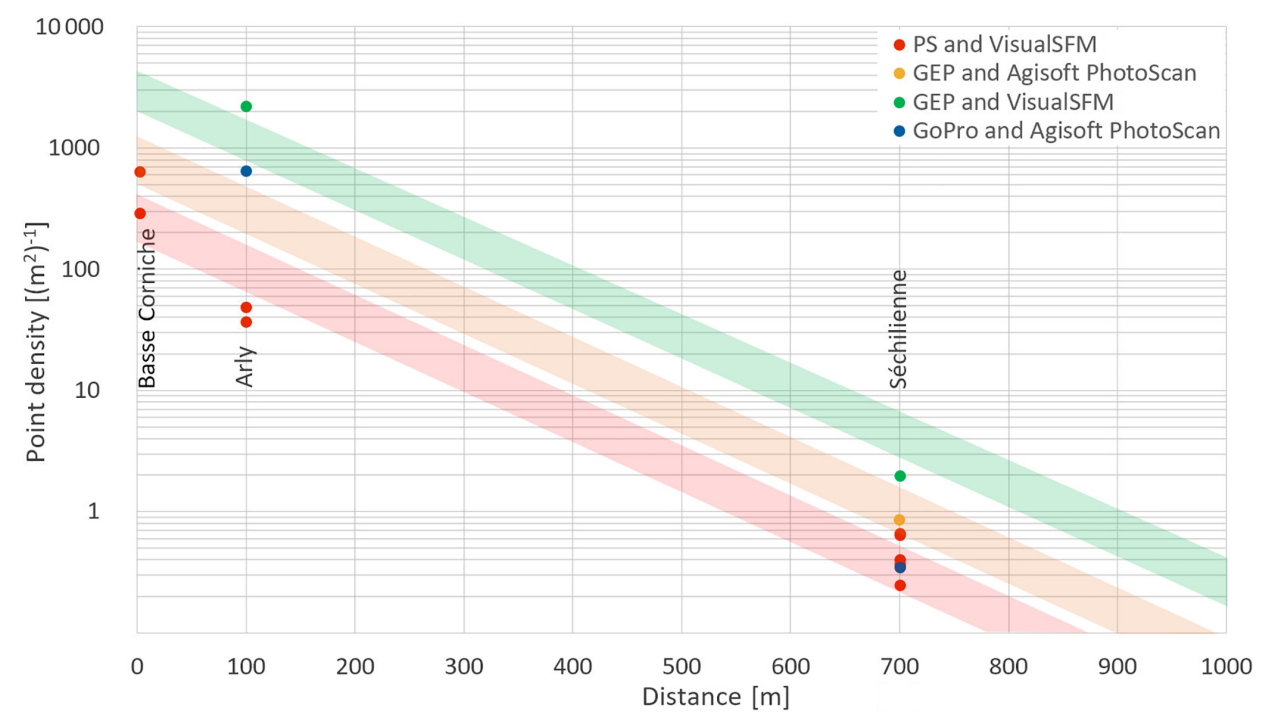

Figure 8. Correlation between the distance from the camera to the case studies and the expected density of points from the three case studies. The red dots are results of the three case studies point clouds obtained from Google Street View (GSV) print screens (PS) in Google Maps (GM) processed with VisualSFM. The red strip represents the corresponding trend based on a negative exponential function. The orange dot is the result of the Séchilienne point cloud obtained from GSV images saved in Google Earth Pro (GEP) processed with VisualSFM. The orange strip represents the corresponding trend based on a negative exponential function. The green dots are the results of the Séchilienne and Arly point clouds obtained from GSV images saved in GEP, processed with Agisoft PhotoScan. The green strip represents the corresponding trend based on a negative exponential function. To compare, the blue dots represent the result of the Séchilienne and Arly point clouds obtained with GoPro action camera images taken on the field and processed with Agisoft PhotoScan.

prove the processing. Information on the picture source, date, point density and program used is given in Table 1.

A strong limiting factor at this site is the non-optimal camera locations. Indeed, the location of the cliff above a tunnel portal does not allow for a lateral movement between the camera positions with regard to the cliff. The maximal viewing angle (in blue in Fig. 2 a) is about $35^{\circ}$ compared to $170^{\circ}$ for site 1 and $115^{\circ}$ for site 2, i.e. 3 to 5 times smaller than for the other studied sites.

\subsection{Discussion}

With the experience acquired during the research, we can highlight the following recommendations to improve results of SfM-MVS with SVI images. (a) Firstly, the distance between the image point of view and the subject as well as the size of the subject are important because they influence the pixel size of the subject. In case study 1 , the location of the cliff next to the road $(<1 \mathrm{~m})$ allows us to get images with a good resolution for the studied object. In case study 2, the area under investigation is too far from the road (500$1400 \mathrm{~m}$ ) and small structures cannot be seen in the landslide. (b) Secondly, the ability to look at the scene from different angles (Fig. 2a) is a determining factor to obtain good results. The greater this viewing angle is, the better the results will be. Case study 1 with a view angle of almost $180^{\circ}$ is optimal because the object is observable from half a circle. The view angle of case study $2\left(115^{\circ}\right)$ is enough to get many different views of the subject from different angles. The view angle is too narrow to have enough different points of view of the cliff in case study $3\left(35^{\circ}\right)$. (c) Thirdly, results are influenced by the image quality and especially by their exposition, contrast and type of sensor, which have been progressively improved during the last few years. Image quality varies considerably for different image sets. Case study 1 is again the best study case in term of image quality. Both image sets have optimal solar exposition and shadows are not strong. Case study 2 has sets with very different images quality. Some sets are well exposed, while others are not. Clouds are present on few image sets. For case study 3 , we have a lot of over- and underexposed images due to the location of the site (incised valley with a southwest-oriented slope with a lot of light or shadow). The problem of image quality must concern Google too since the company removed very underexposed GSV images taken in August 2014 at site 3 from Google Maps at the end of 2016.

According to our findings, small landslides and rockfalls $\left(<0.5 \mathrm{~m}^{3}\right)$ can be detected when the slope or the cliff is close to the road $(0-10 \mathrm{~m})$, as it was shown at site 1 . Conversely, large slope movements and collapses $\left(>1000 \mathrm{~m}^{3}\right)$ can be detected when the studied area is far away from the road (up to $0.5-1 \mathrm{~km}$ ), like site 2 . At such sites, small changes $\left(<1 \mathrm{~m}^{3}\right)$ can correspond to either real rockfalls or errors resulting from processing, like on the toe of almost all 3-D point clouds of the Séchilienne landslide (Fig. 5a2-h2). The measured differences between the point clouds on stable ar- 


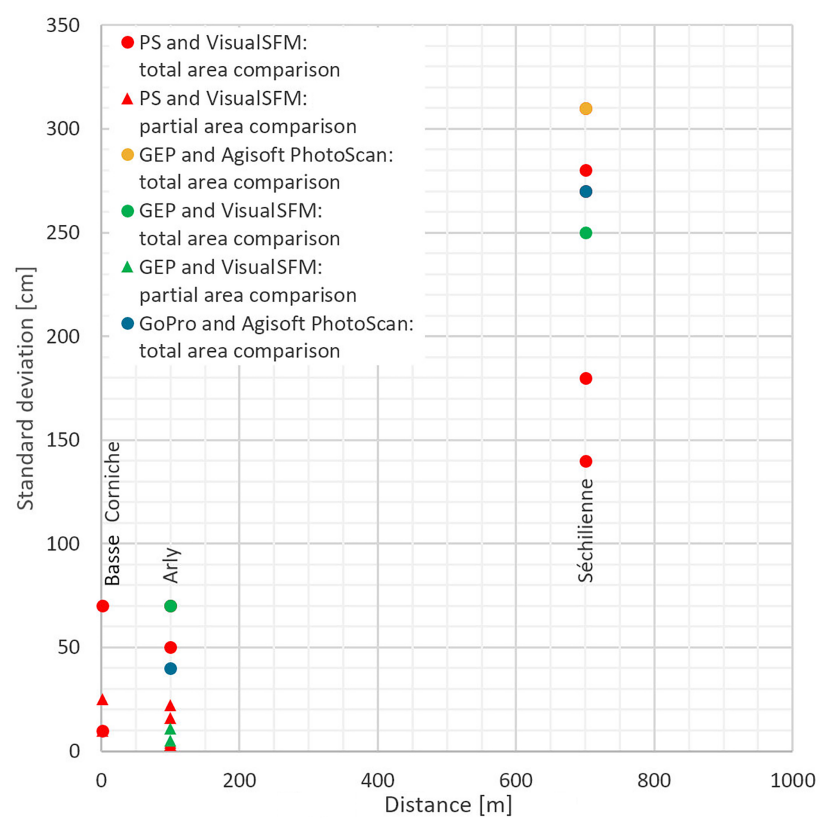

Figure 9. Correlation between the distance from the camera to the case studies and the expected standard deviation from the three case studies. The dots are results of point cloud comparisons on the entire point cloud areas (Table 1). The triangles are the results of point cloud comparisons on partial point cloud area (Table 2). The red dots and triangles are the results of the three case studies' point clouds obtained from Google Street View (GSV) print screens (PS) in Google Maps (GM), processed with VisualSFM compared on the entire area. The orange dot is the result of the Séchilienne point cloud obtained from GSV images saved in Google Earth Pro (GEP) processed with VisualSFM. The green dots and triangles are the results of the Séchilienne and Arly point clouds obtained from GSV images saved in GEP, processed with Agisoft PhotoScan. To compare, the blue dots represent the result of the Séchilienne and Arly point clouds obtained with GoPro action camera images taken on the field and processed with Agisoft PhotoScan.

eas show interesting results when the point cloud alignment is well done. Thus, we observed standard deviations of a few decimetres in stable areas at site 1 (Fig. 3d), between 0.5 and $1.1 \mathrm{~m}$ at site 2 and between 11 and $22 \mathrm{~m}$ at the tunnel entry on site 3. Standard deviations increase at site 2 when point clouds are compared to their entire surface (Fig. 5a2-h2, Table 1). This is attributable to the occurrence of slope movements generating material increase or decrease and thereby increasing standard deviations of the distance between the two compared point clouds. It can also be due to a bad 3$\mathrm{D}$ point cloud alignment. Indeed, cloud alignment is not always easy on some point clouds because of low point density, voids in the point clouds (like in the landslide toe in Fig. 5f2) and the roughness of the terrain. In such difficult alignment cases, we tried to align the point clouds on stable parts where point density was high.

Our study highlighted important differences in 3-D model reconstruction using different software, comparing with pre- vious works (Micheletti et al., 2015; Gómez-Gutiérrez et al., 2015, Niederheiser et al., 2016). Agisoft PhotoScan performed better than VisualSFM when using both GSV images from Google Earth Pro (Fig. $5 f-g$ ) and pictures acquired from a GoPro Hero camera (Fig. 5h). Nevertheless, VisualSFM performed better than Agisoft PhotoScan on print screen captures from SVI. The only difference between these sources of information is the resolution: $2.3 \mathrm{Mpx}$ for print screens from Google Maps, 16.8 Mpx for images saved from Google Earth Pro and $12 \mathrm{Mpx}$ for GoPro camera, stressing the importance of picture resolution to the quality of the 3-D model.

The point density was evaluated according to the distance between the image point of view and the subject and the image types and processing software. The obtained results and the derived trends indicate that the use of GSV images from Google Earth Pro with VisualSFM increases the point density by a factor of 2 compared to the processing of GSV print screens with VisualSFM. The processing of GSV images from Google Earth Pro with Agisoft PhotoScan increases the point density by a factor of 10 compared to the processing of GSV print screens with VisualSFM (trend strips in Fig. 8). The expected point density of the 3-D point clouds from GSV print screens processed in VisualSFM of a subject located a few metres from the camera (Basse Corniche dots in Fig. 8) is about 300 points $\mathrm{m}^{-2}$, about 50 points $\mathrm{m}^{-2}$ for an area located at about $100 \mathrm{~m}$ (Arly dots in Fig. 8) and about 0.5 point $\mathrm{m}^{-2}$ for an area located at about $700 \mathrm{~m}$ (Séchilienne dots in Fig. 8).

Despite the abovementioned prospects, some drawbacks were also observed. The main limitation found in this study is that SfM-MVS processing is designed to retrieve the internal orientation of standard cameras, whereas the images used in this research do not correspond to a standard camera due the construction of the panoramas. Indeed, the main problem comes from the different deformations on GSV print screens or images due to the panoramas construction. The radial deformations on each image, which are stronger than common camera lens, like on fisheye images from GoPro cameras, can be processed without limitation with SfM software like Agisoft PhotoScan. In addition, images from GSV are often over- or underexposed (case study 3 ) and their resolution is low for distant subjects (cases study 2 and 3), making it difficult to obtain results with decimetric accuracy with these constraints. Making zoomed print screens from GSV images does not allow increasing the SfM-MVS process results (case study 2) due to a low image resolution. Finally, the spatial repartition of SVI is often problematic because there are not enough images along the track path and because the road path does not often allow obtaining an efficient strategy concerning the camera positions around the studied area (case study 3). Access to original (raw) images together with valuable data of camera calibration would considerably help to derive 3-D point clouds from GSV using modern photogrammetric workflows. 
A simple development to improve our proposed approach would be for Google to add the back-in-time function to Google Earth Pro. In this case, it would be possible to save GSV images from any proposed time period and to process those images with Agisoft PhotoScan (Fig. 5g) and thus obtain better results than using VisualSFM (Fig. 5f). Since Google services and functionalities of Google Maps and Google Earth evolve over time, it is possible that SfMMVS with GSV images will be more efficient and easier in the near future.

\section{Conclusions}

In this study it was possible to detect and characterise small landslides and rockfalls $\left(<0.5 \mathrm{~m}^{3}\right)$ for study areas relatively close to the road (from 0 to $10 \mathrm{~m}$ ); complementarily, it was possible to detect large-scale landslides or rock collapses $\left(>1000 \mathrm{~m}^{3}\right)$ over areas located far away from the road $(100 \mathrm{~m}$ or more). This information is of great interest when no other data of the studied area have been obtained.

The proposed methodology provides interesting but challenging results due to some constraints linked to the quality of the input imagery. The inconsistent image deformations and the impossibility of extracting the original images from a street view provider are the most important limitations for 3-D model reconstruction derived from SVI. The following constraints strongly limit the proposed approach: large distances between the camera position and the subject of investigation, presence of obstacles between the studied area and the road, image quality, poor meteorological conditions, non-optimal images repartition, reduced number of images, and the existence of shadows and/or highlighted areas. The quality of the final product was observed to be mainly dependent on the image quality and the distance between the studied area and image perspectives.

Despite the abovementioned limitations, SfM-MVS with SVI can be a useful tool in geosciences to detect and quantify slope movements and displacements at an early stage of the research by comparing datasets taken at different time series. The main interest of the proposed approach is the possibility to use archival imagery and deriving 3-D point clouds of an area that has not been captured before the occurrence of a given event. This will allow expanding the database on rock slope failures, especially for slope changes along roads with conditions that are favourable for the proposed approach.

Data availability. Point cloud data presented used in this paper are available on demand.

Competing interests. The authors declare that they have no conflict of interest.
Acknowledgements. The second author was funded by the H2020 Program of the European Commission through Marie SkłodowskaCurie Individual Fellowships (MSCA-IF-2015-705215).

Edited by: Thomas Glade

Reviewed by: Olga Mavrouli and Matt Lato

\section{References}

Abellán, A., Oppikofer, T., Jaboyedoff, M., Rosser, N. J., Lim, M., and Lato, M. J.: Terrestrial laser scanning of rock slope instabilities, Earth Surf. Proc. Land., 39, 80-97, 2014.

Agisoft, L. L. C.: Agisoft PhotoScan user manual, Professional edition, version 1.2.6, 2015.

Anguelov, D., Dulong, C., Filip, D., Frueh, C., Lafon, S., Lyon, R., Ogale, A., Vincent, L., and Weaver, J.: Google Street View: Capturing the world at street level, Computer, 43, 32-38, 2010.

Carrivick, J. L., Smith, M. W., and Quincey, D. J.: Structure from Motion in the Geosciences, John Wiley \& Sons, Pondicherry, India, 2016.

Dubois, L., Chanut, M.-A., and Duranthon, J.-P.: Amélioration continue des dispositifs d'auscultation et de surveillance intégrés dans le suivi du versant instable des Ruines de Séchilienne, Géologues, 182, 50-55, 2014.

Durville, J.-L., Bonnard, C., and Potherat, P.: The Séchilienne (France) landslide: a non-typical progressive failure implying major risks, J. Mt. Sci., 8, 117-123, 2011.

Eltner, A., Kaiser, A., Castillo, C., Rock, G., Neugirg, F., and Abellán, A.: Image-based surface reconstruction in geomorphometry - merits, limits and developments, Earth Surf. Dynam., 4, 359389, https://doi.org/10.5194/esurf-4-359-2016, 2016.

Favalli, M., Fornaciai, A., Isola, I., Tarquini, S., and Nannipieri, L.: Multiview 3D reconstruction in geosciences, Computers \& Sciences, 44, 168-176, 2011.

Fey, C. and Wichmann, V.: Long-range terrestrial laser scanning for geomorphological change detection in alpine terrain handling uncertainties, Earth Surf. Proc. Land., 42, 789-802, https://doi.org/10.1002/esp.4022, 2017.

Fernández, T., Pérez, J. L., Cardenal, J., Gómez, J. M., Colomo, C., and Delgado, J.: Analysis of Landslide Evolution Affecting Olive Groves Using UAV and Photogrammetric Techniques, Remote Sens., 8, 837, https://doi.org/10.3390/rs8100837, 2016.

Furukawa, Y. and Ponce, J.: Accurate, dense, and robust multiview stereopsis, IEEE T. Pattern Anal., 32, 1362-1376, 2010.

Furukawa, Y., Curless, B., Seitz, S. M., and Szeliski, R.: Towards internet-scale multi-view stereo, Computer Vision and Pattern Recognition (CVPR), 2010 IEEE Conference, 1434-1441, IEEE, 2010.

France 3 : Important éboulement dans les gorges de l'Arly en Savoie, available at : http://france3-regions.francetvinfo.fr (last access: 25 January 2017), 2014

Géoportail: IGN (2016), available at: http://www.geoportail.gouv.fr (last access: 25 January 2017), 2016.

Girardeau-Montaut, D.: CloudCompare (version 2.9), GPL software, available at: http://www.cloudcompare.org (last access: 28 November 2017), 2011.

Gómez-Gutiérrez, Á., de Sanjosé-Blasco, J. J., Lozano-Parra, J., Berenguer-Sempere, F., and de Matías-Bejarano, J.: Does HDR 
pre-processing improve the accuracy of 3D models obtained by means of two conventional SfM-MVS software packages? The case of the Corral del Veleta Rock Glacier, Remote Sens., 7, 10269-10294, 2015.

Google Street View: Understand Street View, 2017, available at: https://www.google.com/maps/streetview/understand, last access: 25 January 2017.

Google Maps: Google Inc. (2017), available at: https://maps.google. com, last access: 25 January 2017.

Google Earth Pro: version 7.1.2.241, Google Inc. (2013), available at: https://www.google.com/earth (last access: 28 November 2017), 2013.

Guerin, A., Abellán, A., Matasci, B., Jaboyedoff, M., Derron, M.H., and Ravanel, L.: Brief communication: 3-D reconstruction of a collapsed rock pillar from Web-retrieved images and terrestrial lidar data - the 2005 event of the west face of the Drus (Mont Blanc massif), Nat. Hazards Earth Syst. Sci., 17, 12071220, https://doi.org/10.5194/nhess-17-1207-2017, 2017.

James, M. R. and Robson, S.: Straightforward reconstruction of $3 \mathrm{D}$ surfaces and topography with a camera, Accuracy and geosciences application, J. Geophys. Res., 117, F03017, https://doi.org/10.1029/2011JF002289, 2012.

Klingner, B., Martin, D., and Roseborough, J.: Street View Motionfrom-Structure-from-Motion, Proceedings of the International Conference on Computer Vision, IEEE, 2013.

Kromer, R., Abellán, A., Hutchinson, J., Lato, M., Edwards, T., and Jaboyedoff, M.: A 4D Filtering and Calibration Technique for Small-Scale Point Cloud Change Detection with a Terrestrial Laser Scanner, Remote Sens., 7, 13029-13052, https://doi.org/10.3390/rs71013029, 2015.

Le Roux, O., Schwartz, S., Gamond, J. F., Jongmans, D., Bourles, D., Braucher, R., Mahaney, W., Carcaillet, J., and Leanni, L.: CRE dating on the head scarp of a major landslide (Séchilienne, French Alps), age constraints on Holocene kinematics, Earth Planet. Sc. Lett., 280, 236-245, 2009.

Lowe, D.: Object recognition from local scale-invariant features, International Conference of Computer Vision, Corfu Greece, 1150-1157, 1999.

Lucieer, A., de Jong, S., and Turner, D.: Mapping landslide displacements using Structure from Motion (SfM) and image correlation of multi-temporal UAV photography, Prog. Phys. Geog., 38, 97-116, 2013.

Luhmann, T., Robson, S., Kyle, S., and Boehm, J.: Close-range photogrammetry and 3D imaging, Walter De Gruyter, Berlin/Boston, 2014.

Micheletti, N., Chandler, J. H., and Lane, S. N.: Investigating the geomorphological potential of freely available and accessible Structure-from-Motion photogrammetry using a smartphone, Earth Surf. Proc. Land., 40, 473-486, 2015.

Nice-Matin : La basse corniche coupée en direction de Monaco après un éboulement, available at : http://www.nicematin.com/menton/ (last access: 15 October 2015), 2014.

Niederheiser, R., Mokroš, M., Lange, J., Petschko, H., Prasicek, G., and Elberink, S. O.: Deriving 3d Point Clouds from Terrestrial Photographs-Comparison of Different Sensors and Software. International Archives of the Photogrammetry, Remote Sensing and Spatial Information Sciences-ISPRS Archives, 41, 685-692, 2016.
Oppikofer, T., Jaboyedoff, M., Blikra, L., Derron, M.-H., and Metzger, R.: Characterization and monitoring of the Åknes rockslide using terrestrial laser scanning, Nat. Hazards Earth Syst. Sci., 9, 1003-1019, https://doi.org/10.5194/nhess-9-1003-2009, 2009.

Rosser, N. J., Petley, D. N., Lim, M., Dunning, S. A., and Allison, R. J.: Terrestrial laser scanning for monitoring the process of hard rock coastal cliff erosion, Q. J. Eng. Geol. Hydroge., 38, 363375, 2005.

Royán, M. J., Abellán, A., Jaboyedoff, M., Vilaplana, J. M., and Calvet, J.: Spatio-temporal analysis of rockfall pre-failure deformation using Terrestrial LiDAR, Landslides, 4, 697-709, 2014.

Ruggles, S., Clark, J., Franke, K. W., Wolfe, D., Reimschiissel, B., Martin, R. A., Okeson, T. J., and Hedengren, J. D.: Comparison of SfM computer vision point clouds of a landslide derived from multiple small UAV platforms and sensors to a TLSbased model, Journal of Unmanned Vehicle Systems, 4, 246265, 2016.

Snavely, N.: Scene reconstruction and visualization from Internet photo collections, unpublished $\mathrm{PhD}$ thesis, University of Washington, USA, 2008.

Snavely, N., Seitz, S. M., and Szeliski, R.: Photo Tourism: Exploring Photo Collection in 3D, SIGGRAPH, 6, 835-846, 2006.

Snavely, N., Seitz, S., and Szeliski, R.: Modeling the World from Internet Photo Collections Int. J. Comput Vision, Springer Netherlands, 80, 189-210, 2008.

Streetside: Microsoft Inc. (2017), available at: https://www. microsoft.com/maps/streetside.aspx, last access: 25 January 2017.

Stumpf, A.: Ground-based multi-view photogrammetry for the monitoring of landslide deformation and erosion, Geomorphology, 231, 130-145, 2015.

Tencent Maps: Tencent Inc. (2017), available at: http://map.qq.com, last access: 25 January 2017.

Turner, D., Lucieer, A., and Watson, C.: An Automated Technique for Generating Georectified Mosaics, from Ultra-High Resolution Unmanned Aerial Vehicle (UAV), Conference on 3D Imaging, Modeling, Processing, Visualization \& Transmission Imagery, Based on Structure from Motion (SfM) Point Clouds, Remote Sensing, 4, 1392-1410, 479-486, 2012.

Walstra, J., Chandler, J. H., Dixon, N., and Dijkstra, T. A.: Aerial photography and digital photogrammetry for landslide monitoring, Geological Society, London, Special Publications, 283, 5363, 2007.

Wang, C.-P., Wilson, K., and Snavely, N.: Accurate Georegistration of Point Clouds Using Geographic Data, 3D Vision - 3DV, IEEE, 33-40, 2013.

Westoby, M. J., Brassington, J., Glasser, N. F., Hambrey, M. J., and Reynolds, J. M.: "Structure-from-Motion" photogrammetry: A low-cost, effective tool for geoscience applications, Geomorphology, 179, 300-314, 2012.

Wu, C.: VisualSFM: A visual structure from motion system, available at: http://ccwu.me/vsfm (last access: ä 25 January 2017), 2011.

Zamir, A. R. and Shah, M.: Accurate Image Localization Based on Google Maps Street View, Computer Vision - ECCV 2010, Springer, 255-268, Orlando, USA, 2010. 